\title{
KONODONTOVÁ FAUNA SPODNÍHO TOURNAI V LESNÍM LOMU (BRNO-LÍŠEŇ)
}

\author{
Conodont fauna of Lower Tournaisian in the Lesní lom Quarry (Brno-Líšeň)
}

Vojtěch Cígler, Tomáš Kumpan

Ústav geologických věd PřF MU, Kotlárská 2, 61137 Brno; e-mail:vojtech.cigler@csw.cz, kumpan.tom@gmail.com

(24-41 Vyškov)

Key words: Moravian Karst, Líšeň Formation, Tournaisian, biostratigraphy, conodonts

Abstract

\begin{abstract}
Early Tournaisian was a period of transition between Devonian hot and Carboniferous cold climate system and therefore crucial in terms of global reconstruction of evolution. Early Tournaisian represents a period that follows in detail studied Hangenberg crisis (late Famenian) and that is connected to glaciation. Based on the study of conodont fauna this article outlines the biostratigraphy of the Lower Tournaisian “Upper” Krrtiny limestones situated in the Lesní lom quarry. „Upper" Kŕtiny limestones are pale grey mud calciturbidites containing abundant microfauna of conodonts, echinoderms, ostracods, brachiopods, bivalves, bryozoans, ichthyoliths, radiolarians, trilobites and foraminifera. They are part of the Líšen Formation which belongs to Paleozoic of the Moravian Karst. 8 samples were taken and evaluated from three sections. In total there were determined 22 conodont species belonging to conodont genera Bispathodus, Polygnathus, Pseudopolygnathus and Siphonodella. Following taxons were found: Siphonodella belkai DZIK 1997, Si. carinthiaca SCHÖNLAUB 1970, Si. cf Si. isosticha COOPER 1939, Si. duplicata-jii, Si. jii (Ji 1985), Si. kalvodai KAISER, KUMPAN \& CÍGLER 2017, Si. lobata BRANSON \& MEHL 1934b, Si. obsoleta HASS 1959, Si. sandbergi (M1, M2) KLAPPER 1966, Polygnathus communis communis BRANSON \& MEHL 1934b, Po. distortus BRANSON \& MEHL 1934b, Po. inornatus BRANSON 1934, Po. purus purus VOGES 1959, Po. spicatus BRANSON 1934, Po. vogesi ZIEGLER 1962, Pseudopolygnathus fusiformis BRANSON \& MEHL 1934b, Ps. primus BRANSON \& MEHL 1934, Ps. triangulus inaequalis VOGES 1959 and Ps. triangulus triangulus VOGES 1959. Based on the conodont elements the Siphonodella jii and Siphonodella sandbergi zones were distinguished. Conodont association of studied sections 1 and 2 belonged to the siphonodellid-polygnathid biofacies.
\end{abstract}

Úvod

Rané tournai bylo obdobím přechodu mezi devonským teplým a karbonským chladným klimatickým režimem, a proto je klíčové z pohledu rekonstrukcí vývoje globálních ekosystémů. Rané tournai představuje období mezi detailně studovanou hangenberskou krizí na konci famenu a středně tournaiskými událostmi, které byly spojené s ochlazením a následnou glaciací (Isaacson et al. 1999; Saltzman 2002; Kaiser et al. 2015). $\mathrm{Na}$ toto raně tournaiské období je zaměřen multioborový (biostratigrafie, geochemie, petrofyzika) stratigrafický výzkumný projekt, jehož cílem je zpřesnění globální stratigrafické korelace a rekonstrukce možných glacioeustatických výkyvů. Tato zpráva přináší detailní data o výskytech konodontů na nově studovaných profilech spodního tournai z Lesního lomu v Brně-Líšni, které jsou světově unikátní společným výskytem strati- graficky významných konodontů a foraminifer (Kalvoda et al. 2015). Raně tournaiský ekosystém byl výrazně ovlivněn hangenberskou biotickou krizí, která způsobila vyhynutí nejméně $21 \%$ marinních rodů (Sepkoski 1996). Nepřežily ji významné devonské rody konodontů Palmatolepis a Icriodus (Simakov 1993), které v tournai

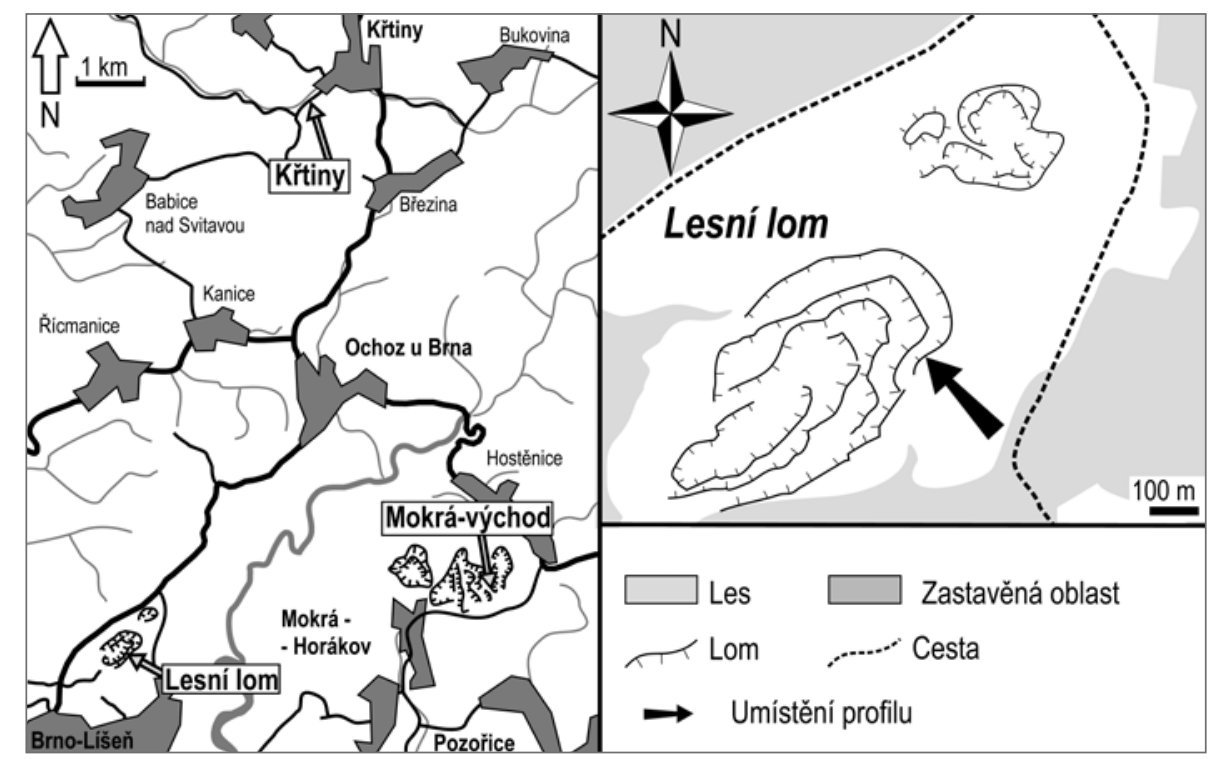

Obr. 1: Schematická mapa studované oblasti.

Fig. 1: Schematic map of studied area. Legend: les = forest, zastavěná oblast = urbanized area, lom = quarry, cesta = road, umístění profilu = location of the section. 


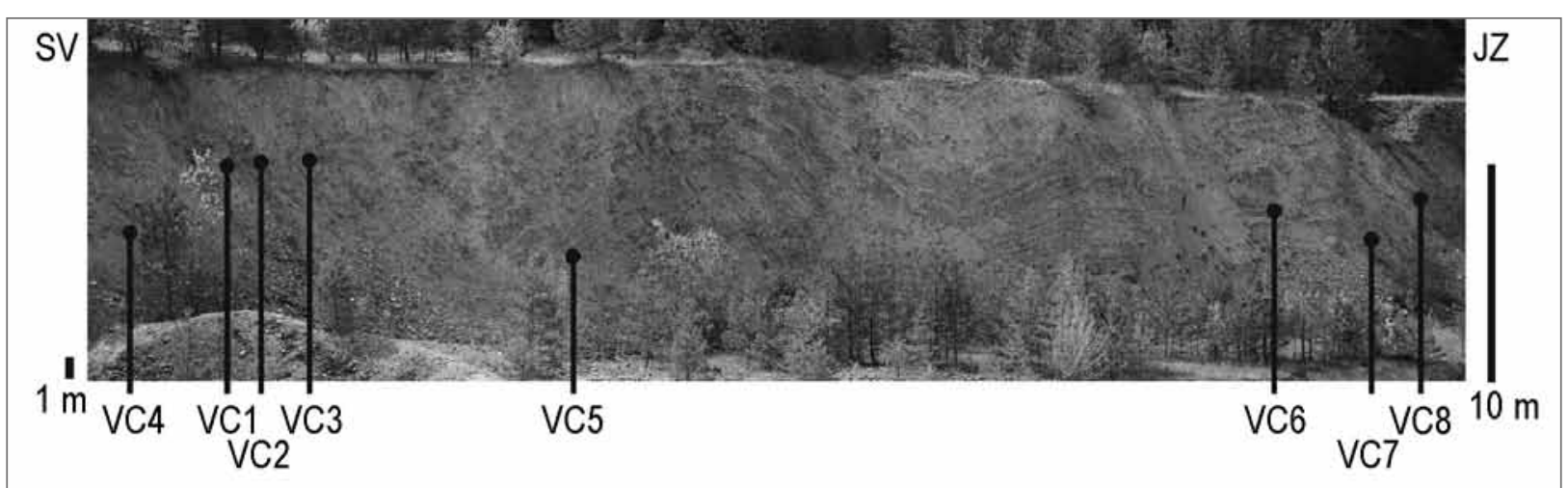

Obr. 2: JV stěna svrchní etáže Lesního lomu s vyznačenými místy odběru vzorků.

Fig. 2: SE side of the upper level of the Lesní lom quarry with marked spots where samples were taken.

nahradil z pohledu biostratigrafie významný rod Siphonodella, jehož výskyt je hojný ve studovaném materiálu, který byl zpracován $\mathrm{v}$ rámci bakalářské práce prvního autora (Cígler 2015).

\section{Materiál a metodika}

Lesní lom je etážový jámový lom nacházející se cca 500 m s. od městské části Brno-Líšeň (obr. 1). Jsou v něm odkryty sledy macošského (frasn) a líšeňského souvrství (famen-tournai). Studovány byly „svrchní “ křtinské vápence líšeňského souvrství, které leží na famenských hádsko-říčských vápencích téhož souvrství (Kalvoda et al. 1996). „Svrchní“ křrtinské vápence jsou tence vrstevnaté a hlíznaté hemipelagické mikritické vápence s vložkami

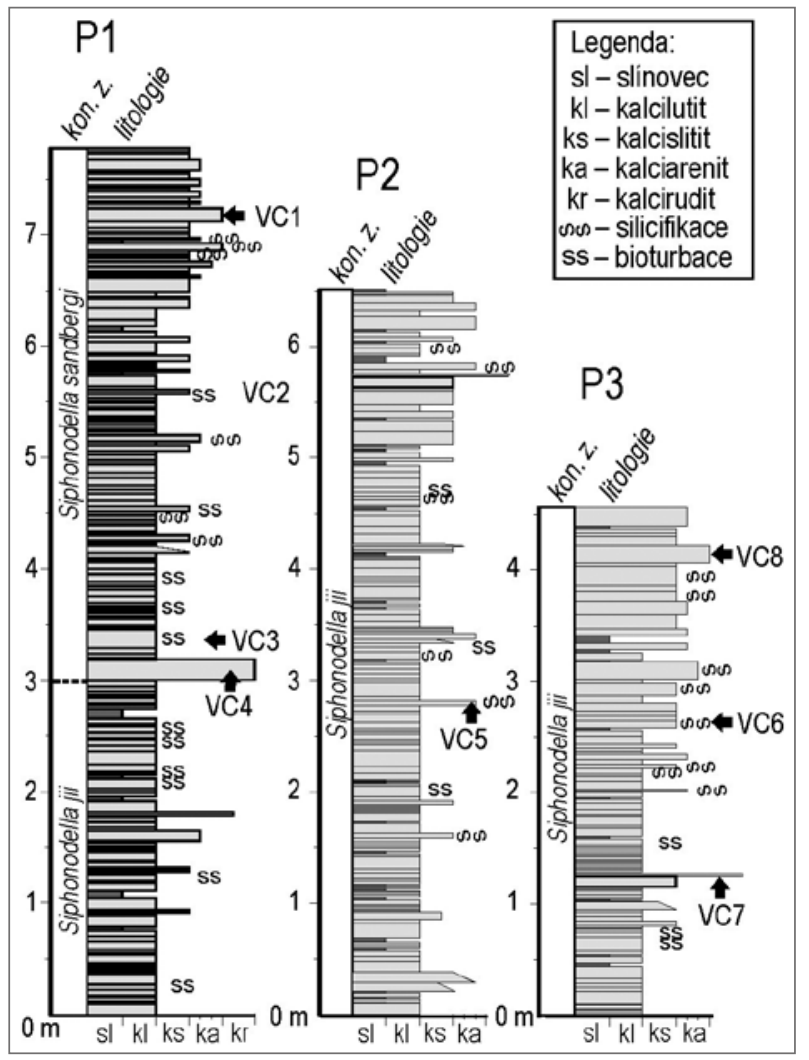

Obr. 3: Litologické schéma profilů P1, P2 a P3. Kon. z. = konodontová zóna.

Fig. 3: Lithological log of the sections P1, P2 and P3. Kon. z. = conodont zone. hrubozrnnějších vápenců, interpretovaných jako kalciturbidity (Kalvoda et al. 1999).

Studovaný sled byl rozdělen na 3 dílčí profily (P1, P2 a P3) v nejvyšší etáži (N 49²2‘29,408“"E 1669‘69,444“), ze kterých bylo odebráno 8 vzorků (VC1 - VC8; obr. 2). Ty byly macerovány v cca $15 \%$ roztoku kyseliny octové. Nerozpustný zbytek byl plaven přes síto o velikosti oka $0,16 \mathrm{~mm}$ a $\mathrm{z}$ přesítovaného materiálu byly následně vybírány mikrofosilie pod binokulární lupou. V tomto článku je použita revidovaná „pelagická“ zonace sensu Becker et al. (2016).

\section{Výsledky \\ Popis profilu}

Vrstevní sled (obr. 3) je tvořen kalcilutity až kalcisiltity (mocnost 1-20 cm), stř́ídajícími se s tenkými vložkami kalovců a slínovců $(1-5 \mathrm{~cm})$. Vápence mají šedou až světle šedou barvu, jsou deskovité, často hlíznaté (obr. 4), hojné jsou také stopy po bioturbaci. Kalovce jsou okrové až šedé. Jako občasné vložky se vykytují vrstvy kalciarenitů až intraklastických kalciruditů $(1-20 \mathrm{~cm})$.

\section{Konodontová biostratigrafie}

Ve studovaných vzorcích byli kromě konodontů nalezeni echinodermáti, ostrakodi, brachiopodi, bivalvie,

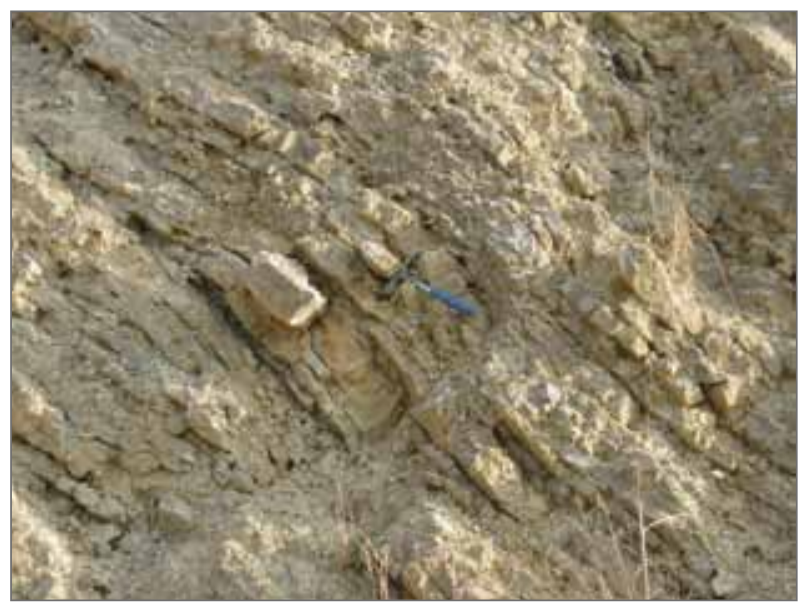

Obr. 4: Detail „svrchních“ "křtinských vápenců (spodní tournai). Fig. 4: Detail of the „upper“ Krrtiny limestones (lower Tournaisian). 
bryozoa, ichtyolity, radiolárie, trilobiti a foraminifery. Mezi konodonty převažovali zástupci rodů Polygnathus, Pseudopolygnathus a Siphonodella, méně častý byl rod Bispathodus. Celkově bylo nalezeno 566 platformních konodontů. Množství konodontových elementů $\mathrm{v}$ jednotlivých vzorcích je uvedeno v tabulce 1 , vybraní zástupci jsou na obrázku 5.

Vzorky z profilu P3 obsahovaly taxony konodontů Siphonodella belkai DZIK 1997, Si. carinthiaca SCHÖNLAUB 1970, Si. duplicata-jii, Si. lobata BRANSON \& MEHL 1934b, Si. kalvodai KAISER, KUMPAN \& CÍGLER 2017, Polygnathus inornatus BRANSON 1934, Po. purus purus VOGES 1959, Pseudopolygnathus primus BRANSON \& MEHL 1934 a Ps. triangulus VOGES 1959. Tato asociace odpovídá zóně Siphonodella jii (= svrchní Siphonodella duplicata $=$ Si. hassi) výskytem jejího indexového taxonu Si. jii (Ji 1985), spolu s Polygnathus vogesi ZIEGLER 1962, který nepokračuje do mladších zón (Bardasheva et al. 2004).

Vzorek VC5 z profilu P2 obsahoval taxony Po. distortus, Po. inornatus, Po. purus purus, Ps. fusiformis, Ps. primus, Ps. triangulus a Si. jii, které dokládají opět zónu Siphonodella jii.

Vrstevní sled profilu P1 byl již zařazen do mladší zóny Si. sandbergi, a to na základě výskytu indexového taxonu Si. sandbergi

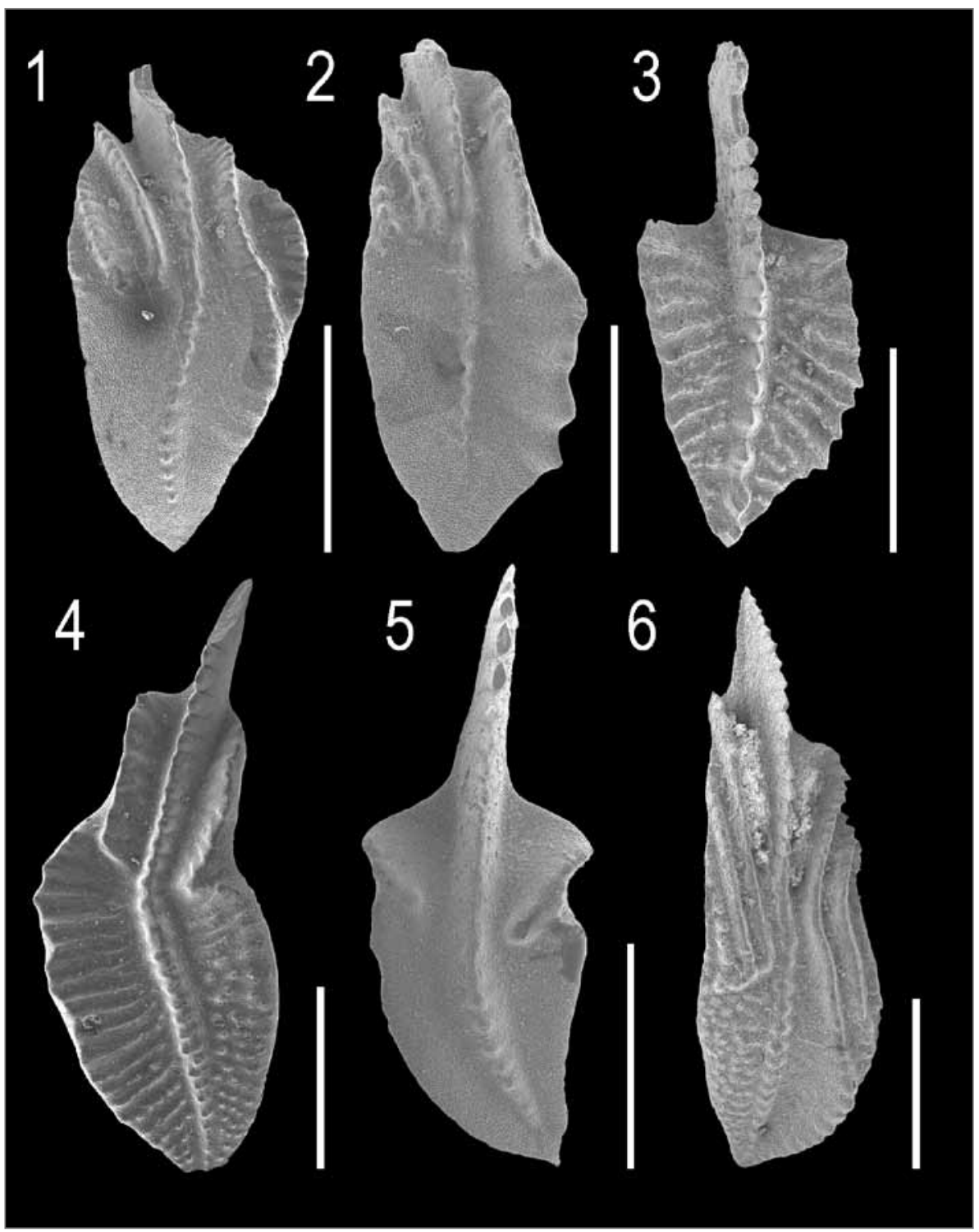

Obr. 5: Nejvýznamnější konodontové elementy ze studovaných profilů. 1. Siphonodella belkai DZIK 1997 (VC7, zóna Siphonodella jii); 2. Si. kalvodai KAISER, KUMPAN \& CÍGLER 2017 (VC7, zóna Siphonodella jii); 3. Pseudopolygnathus triangulus triangulus VOGES 1959 (VC4, zóna Siphonodella sandbergi); 4. Siphonodella jii (Ji 1985) (VC7, zóna Siphonodella jii); 5. Polygnathus vogesi ZIEGLER 1962 (VC7, zóna Siphonodella jii); 6. Siphonodella sandbergi KLAPPER 1966 (VC4, zóna Siphonodella sandbergi). Měŕítko odpovídá $500 \mu \mathrm{m}$.

Fig. 5: The most important conodonts from the studied sections. 1. Siphonodella belkai DZIK 1997 (VC7, zone Siphonodella jii); 2. Si. kalvodai KAISER, KUMPAN \& CÍGLER 2017 (VC7, zone Siphonodella jii); 3. Pseudopolygnathus triangulus triangulus VOGES 1959 (VC4, zone Siphonodella sandbergi); 4. Siphonodella jii (Ji 1985) (VC7, zone Siphonodella jii); 5. Polygnathus vogesi ZIEGLER 1962 (VC7, zone Siphonodella jii); 6. Siphonodella sandbergi KLAPPER 1966 (VC4, zone Siphonodella sandbergi). Graphic scale $500 \mu \mathrm{m}$.

KLAPPER 1966 a Ps. triangulus triangulus VOGES 1959. Si. sandbergi byla v Lesním lomu nalezena v obou morfotypech. Dále byly ve vzorcích zastoupeny taxony Siphonodella belkai DZIK 1997, Si. cf Si. isosticha COOPER 1939, Si. obsoleta HASS 1959, Polygnathus communis communis BRANSON \& MEHL 1934b, Po. distortus BRANSON \& MEHL 1934b, Po. inornatus BRANSON 1934, Po. purus purus VOGES 1959, Po. spicatus BRANSON 1934, Pseudopolygnathus fusiformis BRANSON \& MEHL 1934b a Ps. triangulus inaequalis VOGES 1959.
Na základě procentuálního zastoupení jednotlivých rodů (tab. 1) byly určeny konodontové biofacie. Ve všech třech profilech přesáhlo zastoupení rodu Siphonodella $25 \%$ a spolu s rodem Polygnathus tvořilo více jak $50 \%$. Studovaná společenstva lze zařadit do biofacie siphonodellid-polygnathidové, která indikuje sedimentační prostředí mořské pánve, jejího úpatí a svahu (Ji 1985).

\section{Diskuze a závěr}

$\mathrm{Na}$ základě konodontové fauny byly „svrchní“ křtinské vápence na studovaných profilech Lesního lomu 
Tab. 1: Procentuální zastoupení rodů na studovaných profilech. Celkové množství konodontů v jednotlivých vzorcích je v závorkách. Zkratky rodů konodontů: Bi. = Bispathodus, Po. $=$ Polygnathus, Ps. = Pseudopolygnathus, Si. = Siphonodella . Tab. 1: Percentage proportion of genera in studied sections. Total amount of platform conodonts is in brackets. Abbreviation of the conodonts genera: Bi. = Bispathodus, Po. = Polygnathus, Ps. $=$ Pseudopolygnathus, Si. $=$ Siphonodella.

\begin{tabular}{|l|c|c|c|c|c|}
\hline & $\begin{array}{c}\text { Bi. } \\
(\%)\end{array}$ & $\begin{array}{c}\text { Po. } \\
(\%)\end{array}$ & $\begin{array}{c}\text { Ps. } \\
(\%)\end{array}$ & $\begin{array}{c}\text { Si. } \\
(\%)\end{array}$ & $\begin{array}{c}\text { Si. }+ \text { Po. } \\
(\%)\end{array}$ \\
\hline P1 (299) & $\mathbf{0 , 6 7}$ & $\mathbf{3 5 , 7 9}$ & $\mathbf{1 7 , 0 6}$ & $\mathbf{4 6 , 4 9}$ & $\mathbf{8 2 , 2 7}$ \\
\hline VC1 (157) & 1,27 & 21,66 & 19,75 & 57,32 & 78,98 \\
\hline VC2 (32) & 0,00 & 21,88 & 28,13 & 50,00 & 71,88 \\
\hline VC3 (14) & 0,00 & 28,57 & 21,43 & 50,00 & 78,57 \\
\hline VC4 (96) & 0,00 & 64,58 & 8,33 & 27,08 & 91,67 \\
\hline P2 (64) & $\mathbf{3 , 1 3}$ & $\mathbf{5 3 , 1 3}$ & $\mathbf{2 0 , 3 1}$ & $\mathbf{2 3 , 4 4}$ & $\mathbf{7 6 , 5 6}$ \\
\hline VC5 (64) & 3,13 & 53,13 & 20,31 & 23,44 & 76,56 \\
\hline P3 (203) & $\mathbf{0 , 9 9}$ & $\mathbf{5 5 , 6 7}$ & $\mathbf{9 , 3 6}$ & $\mathbf{3 3 , 9 9}$ & $\mathbf{8 9 , 6 6}$ \\
\hline VC6 (34) & 2,94 & 64,71 & 0,00 & 32,35 & 97,06 \\
\hline VC7 (122) & 0,82 & 59,02 & 11,48 & 28,69 & 87,70 \\
\hline VC8 (47) & 0,00 & 40,43 & 10,64 & 48,94 & 89,36 \\
\hline
\end{tabular}

zařazeny do rozsahu zón Si.jii až Si. sandbergi. Tyto zóny jsou $\mathrm{z}$ křtinských vápenců Moravského krasu známé $\mathrm{z}$ několika lokalit, např̀ z lomu u Křtin (Kalvoda et al. 2015), z profilu Anaklety (Rutová 2009) a z dnes již zavezeného lomu V Habeši (Hladil 1987), kde se vyskytují v kondenzovaném hostěnickém litofaciálním vývoji (Rez et al. 2011) a mají mocnosti jen $v$ řádu decimetrů až prvních metrů. Nově studované profily $\mathrm{v}$ Lesním lomu pocházejí $\mathrm{z}$ horákovského litofaciálního vývoje, který má mnohem větší mocnost a lze zde proto sledovat stratigrafickou distribuci fauny v mnohem větším detailu, podobně jako v lomech na Mokré (Kalvoda \& Kumpan 2014).

Zajímavý je nález většího množství exemplářů druhu Si. belkai z vyšších částí zóny Si. jii (obr. 5). Jedná se o platformního konodonta s neornamentovaným (hladkým) posteriorním povrchem, který byl doposud popsán pouze $\mathrm{z}$ východní Evropy, Uralu a v jednom exempláři $z$ dříve studovaného profilu v Lesním lomu (Kalvoda et al. 2015). Díky jeho nově zjištěným výskytům v Moravském krasu a Rýnském břidličném pohoří nabývá tento druh na stratigrafickém významu díky možnosti korelace báze pelagické konodontové zóny Si. jii (= svrchní Si. duplicata nebo Si. hassi) a východoevropské konodontové zóny Si. belkai (Kaiser et al. 2017). Ta byla doposud korelována s mladší zónou Si. sandbergi (Pazukhin 2009). Zvýšení četnosti druhu Si. belkai v rámci krátkého časového úseku uvnitř zóny $S i$. jii je srovnatelné s podobným výskytem ze Svatokř́ižských hor (Dzik 1997). Mezi další důležitá zjištění patří nález tř́i elementů nového druhu Si. kalvodai KAISER, KUMPAN \& CÍGLER 2017 (obr. 5), který byl doposud známý pouze $\mathrm{v}$ jednom exempláři ze středně tournaiské zóny spodní Si. crenulata $\mathrm{z}$ Tádžikistánu (Bardasheva et al. 2004).

\section{Poděkování}

Výzkum byl financován z grantu GAČR 16-11563S Nejranější karbonské greenhouse-icehouse klimatické oscilace - multidisciplinární př́stup. Autoři děkují recenzentưm Jiřimu Kalvodovi a Ladislavu Slavíkovi za podnětné pripomínky. 


\section{Literatura}

Bardasheva, N. P. - Bardashev, I. A. - Weddige, K. - Ziegler, W. (2004): Stratigraphy and conodonts of the Lower Carboniferous of the Shishkat section (southern Tien Shan, Tajikistan). - Senckenbergiana lethaea, 84, 225-301. Frankfurt am Main.

Becker, R. T. - Kaiser, S. I. - Aretz, M. (2016): Review of chrono-, litho- and biostratigraphy across the global Hangenberg Crisis and Devonian-Carboniferous Boundary. - The Geological Society of London.

Cígler, V. (2016): Spodnotournaiská konodontová fauna Lesního lomu v Brně-Líšni. - MS, bakalářská práce. Př́rodovědecká fakulta Masarykovy univerzity. Brno.

Dzik, J. (1997): Emergence and succession of Carboniferous conodont and ammonoid communities in the Polish part of the Variscan sea. - Acta Palaeontologica Polonica, 42, 57-170.

Hladil, J. - Bernardová, E. - Brunnerová, Z. - Brzobohatý, R. - Čekan, V. - Dvořák, J. - Eliáš, M. - Friáková, O. - Havlí̌ek, P. Kalvoda, J. - Klečák, J. - Machatková, B. - Maštera, L. - Mittrenga, P. - Otava, J. - Přichystal, A. - Rejl, L. - Růžička, M. (1987): Vysvětlivky k základní geologické mapě ČR 1 : 25 000, 24-413 Mokrá-Horákov. - Česká geologická služba. Praha.

Isaacson, P. E. - Hladil, J. - Shen, J. W. - Kalvoda, J. - Grader, G. (1999): Late Devonian (Famennian) glaciation in South America and marine offlap on other continents. - Abhandlungen der Geologischen Bundesanstalt, 54, 239-257.

Ji, Q. (1985): Study on the phylogeny, taxonomy, zonation and biofacies of Siphonodella (conodonta). - Institute of Geology, Bulletin 11, 51-75.

Kaiser, S. I. - Aretz, M. - Becker, R. T. (2015): The global Hangenberg Crisis (Devonian-Carboniferous transition): review of a first-order mass extinction. - In: Becker, R. T. - Königshof , P. \& Brett, C. E. (eds): Devonian Climate, Sea Level and Evolutionary Events, Geological Society, 387-437.

Kaiser, S. I. - Kumpan, T. - Cígler, V. (2017): New unornamented siphonodellids (Conodonta) of the lower Tournaisian from the Rhenish Massif and Moravian Karst (Germany and Czech Republic). - Neues Jahrbuch für Geologie und Paläontologie - Abhandlungen 286, 1-33. DOI: 10.1127/njgpa/2017/0684

Kalvoda, J. - Bábek, O. - Nehyba, S. - Špaček, P. (1996): Svrchnodevonské a spodnokarbonské kalciturbididty z Lesního lomu v Brně-Líšni (jižní část Moravského krasu). - Geologické výzkumy na Moravě a ve Slezsku v roce 1995, 98-100. Brno.

Kalvoda, J. - Bábek, O. - Malovaná, A. (1999): Sedimentary and Biofacies Records in Calciturbidites at the Devonian-Carboniferous Boundary in Moravia (Moravian-Silesian Zone, Middle Europe). - Facies, 41, 141-158. Erlangen.

Kalvoda, J. - Kumpan, T. (2014): Nové paleontologické nálezy v lomech cementárny v Mokré v roce 2014. - Českomoravský cement, a.s., $72 \mathrm{~s}$.

Kalvoda, J. - Kumpan, T. - Bábek, O. (2015): Upper Famennian and Lower Tournaisian sections of the Moravian Karst (Moravo-Silesian Zone, Czech Republic): a proposed key area for correlation of the conodont and foraminiferal zonations. - Geological Journal, 50, 17-38.

Pazuchin, V. N. (2009): Konodontovaja zonalnost nižnego karbona južnogo urala i vostoka ruskoj platformy. 200 let Otečestvennoj Paleontologii, Materialy vserosijskogo sovečanija, 96-97. Rossijskaja akademia nauk.

Rez, J. (2010): Strukturně-geologický vývoj jižní části Moravského krasu. - MS, disertační práce. Př́rodovědecká fakulta Masarykovy univerzity. Brno.

Rutová, M. (2009): Konodontová fauna famenu a spodního tournai ve výchozech v údolí Říčky u Brna. - MS, diplomová práce. Př́rodovědecká fakulta Masarykovy univerzity. Brno.

Saltzman, M. R. (2002): Carbon and oxygen isotope stratigraphy of the Lower Mississippian (Kinderhookian-lower Osagean), western United States: Implications for seawater chemistry and glaciation. - Geological Society of America Bulletin, 114, 96-108.

Sepkoski, J. J. (1996): Patterns of Phanerozoic extinction: a perspective from global data bases. - In: Walliser, O. H. (ed.): Global Events and Event Stratigraphy in the Phanerozoic. Springer, Berlin, 35-51.

Simakov, K. V. (1993): The dynamics and biochronological structure of the Hangenbergian bioevent. - Palaeogeography, Palaeoclimatology, Palaeoecology, 104, 127-137. 